\title{
SIMPLICITY AND ACCURACY IN MEASURING PULPWOOD
}

\author{
Presented before the anmual meeting of the Association of Forest Engineers \\ for the Province of Quebec-December the 18th. and 19th., 1935. \\ By W. G. Wrigh't, Forester, Price Bros. Co. Ltd.
}

In general, the measurement of pulpwood is required:-

1. For payment of stumpage due to the government on licensed land.

2. For the internal accounting of the forest operator, where provision must be inade for:-

(a) Payment of contractors.

(b) Determination of costs of wood going into the manufacturing processes.

These objects have not the same requirements. The payment of stumpage is governed by the terms of the license and government regulations on Crown lands. Payment of contractors is governed by the contract, which may be for wood cut on licensed land or for wood cut elsewhere. For determination of costs of wood going into the manufacturing processes the requirements differ with the class of product being made; the requirements are not the same for a mill manufacturing bleached sulphite and for a mill manufacturing kraft.

Measurement of pulpwood going into the manufacturing processes may require a different technique to measurement of pulpwood for payment of government stumpage and may allow more accurate methods; on freehold, measurement of pulpwood for payment of government stumpage is not necessary and, further, some government authorities establish the amount of government dues payable from measurement of the finished product instead of from measurement of wood in the cutting operations.

These notes are intended to outline the problem of measuring pulpwood, first, for payment of government stumpage and, second, to fulfill as far as possible the other requirements set forth above; they refer to the supply of pulpwood to the typical newsprint mill in Eastern Canada with which all present are familiar.

The present Quebec board foot system is simple in application but for measurement of pulpwood it does not fulfill the requirement of accuracy, particularly in respect of determination of costs of pulpwood delivered to the manufacturing processes. It is evident that measurement of pulpwood in solid cubic feet will give more accurate results than measurement under the present board foot system, and I will deal only with measurement of pulpwood in solid cubic feet. 
It will be noted that no mention is made of the measurement of saw logs; Mr. Kennedy in his paper deals with the relative merits of the present Quebec Log Rule and a cubic foot system for measuring saw logs, and I have nothing to add to what he says on the subject.

The operation of measuring pulpwood should be simple, so that costs of measuring may be commensurate with the value of the product. We do not require the same accuracy as is needed for ineasuring more valuable raw material and we must be prepared to sacrifice some accuracy to reduce costs, and the question becomes "How nuch accuracy are we willing to sacrifice for how much simplicity?" The answer to this question must depend upon judgement to a certain extent, but it cannot be answered satisfactorily without some detailed knowledge of the effect of the various sources of error and of the costs of measuring. Costs of measuring are due to administrative as well as technical features, and the one class cannot be divorced from the other; I will confine these notes to the technical side of the problem as much as possible, though it must be emphasised that a decision about the adoption of any system of measurement must depend upon its cost, whether these costs are due to administrative or technical features.

\section{A. ACCURACY}

I will deal with the question of accuracy first, and this resolves itself into a consideration of the sources of error.

\section{Formula for calculating volume.}

Where the log has the same form as a frustrum of a parabaloid, volume based upon measurement of the two ends and length (Smalian's formula) gives a true volume in cubic feet, as does volume based upon measurement of middle diameter and length (Hueber's formula). Text books on the subject may be referred to for details of the effect of deviation in the form of the log from this ideal form. Experiences shows that, on the average, logs have a form more concave than that of a frustrum of a parabaloid, with the consequence that Smalian's formula generally gives too high a measurement and Hueber's too low a measurement, the error heing greater with Smalian's formula. The error from this source is aggravated in butt logs with a pronounced basal flare.

It is not practical in measuring pulpwood to measure the middle diameter of each $\log$ or 4-foot bolt and, consequently, some system upon measurement of the two ends must be used.

The correct use of formula depends upon averaging the basal area of the two ends and multiplying by the length. An error arises where the volume is calculated from the average of the two diameters. 


\section{System of measurement.}

When recording diameters, these can conveniently be classed in 1-inch classes, $1 / 2$-inch classes or $1 / 10$-inch classes. Where it is the practice to record all diameter measurements between one $1 / 2$-inch gradation and the next higher as falling in the class designated by the lower of the two gradations, (c.g. measurements between $51 / 2$ " and 6 " would be classed as $51 / 2$ ") an error arises and this error varies with the distribution of diameters, the volume recorded being about $9 \%$ too low for measurements between $5 \mathrm{I} / 2$ " and $6 "$. Where the same practice is followed in measuring to the nearest $1 \frac{1}{1} 10$-inch the error is less, being about $2 \%$ for diameters of $6 "$. It is more accurate to record diameters in such a way that measurements falling below the half way point between two gradations are classed as falling in the class designated by the lower gradation, while the measurements falling above this point are classed as the higher class. However here again error may arise and from two sources:-

(a) The diameter that represents the true average volume of any particular diameter class falls above the arithmetic average of the diameters; i.e., the true middle point of the 1 -inch diameter class above $5.5^{\prime \prime}$ and helow $6.5^{\prime \prime}$ is higher than $6.0^{\prime \prime}$, and recording the diameter as $6.0^{\prime \prime}$ gives too low a volume.

(b) The distribution of the $\log$ diameters within the inch class may be irregular; in typical pulpwood cuttings, it is general that there are more diameters in the lower half of the inch class (e.g. hetween $5.5^{\prime \prime}$ and $6.0^{\prime \prime}$ ) than there are in the upper half of the inch class (e.g. between 6.0" and 6.5"). Where this condition exists the volume calculated by multiplying the number of logs in the inch class by the volume corresponding to the middle diameter will be too high and this error tends to counterbalance the error mentioned in the preceding paragraph. These errors are less where classification of diameters is in $1 / 2$-inch classes and practically eliminated where diameters are classed in $1 / 10$-inch classes.

\section{Measurements of diameter.}

Apart from errors in instruments used and in the application of them, error may arise as follows:-

(a) Where the cut surface is not perpendicular to the axis of the log, measurement of the cut surface gives too high a volume.

(b) Where the end of the $\log$ is not truly circular, error may arise due to the diameter measured not representing the true area of the surface; if the measurer is biassed (i.e. if he tends to measure a diameter larger or smaller than the true diameter) errors up to $5 \%$ or more may arise; further, calculating volume from the average of the large and small diameters of an eliptical $\log$ always gives too high a measurement. 
(c) Improper trimming of the butt causes difficulty in measuring butt logs and is so liable to cause error.

\section{Defect}

(a) The measurement of the surface of defect at the end of a $\log$ is subject to the same errors as measurement of any other cut surface.

(b) Judgement of the amount of defect from examination of one end of the $\log$ only is more difficult than if the log is identified and the appreciation of the defect in the log based upon the examination of the two ends. Further, apparently sound wood may contain defect that has spread from the neighboring visible defect.

(c) Judgement of the amount of deduction for defect must depend on the purpose for which the pulpwood is intended; pulpwood for a kraft mill can bear a larger proportion of defect than pulpwood for shipment to the United Kingdom; and this deduction can only be made intelligently if the scaler is fully informed about what defect is acceptable.

The above errors arise in measuring solid cubic content of both logs and 4-foot wood. The range of error is not necessarily the sane for the two classes of pulpwood. Further, the error from each of the sources named varies under different conditions, and reliable figures for the range of each error under the different conditions net with can only be obtained after extended study. However, some idea of the probable importance of each source of error can be secured from experience in ordinary operating conditions, and a sufficiently close estimate of these errors is necessary, if we are to develop a system of measurement that will give what we consider to be close enough accuracy in the final result.

We will now turn to a consideration of the other requirement for a satisfactory system of measurement, viz. simplicity. We have touched upon this question already when we decided that it was not practical in woods operations to measure the middle diameter of the $\log$.

\section{B. SIMPLICITY}

I will consider the question under two heads, logs and 4-foot wood:-

\section{Logs}

For measuring solid cubic feet, the most straight-forward and least complicated method is the following:-

(a) Measure the diameter of each log on each side of each pile, classifying the diameters in 1 -inch classes. 
(b) Measure sufficient logs to establish the classification of log lengths in 1-foot classes.

(c) Apply a cubic foot volume table to diameter classes recorded, the volume table fjgure for each diameter class representing the volume for half the length of the log.

This makes no provision for identification of undersize and cull logs; for payment of jobbers and government stumpage, undersized logs must be identified and, if cull $\operatorname{logs}$ are to be left unhauled, they also must be identified. Accordingly, some provision must be made for this in the system of measuring. Also proper evaluation of minor defects is not provided for by this method, but the disadvantage of any error here would probably be off-set by the advantages of doing away with the identification of each $\log$.

The amount of work involved may be reduced by measuring only a proportion of the diameters; the simplest method of reducing the work is to measure the diameters on one side of the pile only, providing at the same time for unbiassed selection of the side of the pile to be measured. The same method would be followed for measuring defect, culls and undersize as in measurement of diameters on both sides of the pile described above. Over a large number of logs the results would be the same for both systems; for small piles scaled for individual choppers there might be some opening for complaint that a particular man was not getting his due.

Other methods for reducing the work have been tried out experimentally and on a commercial scale, notably measurement of all logs above a certain predetermined diameter with count of the rest, and the writer would be interested to learn how they function.

\section{4-foot wood.}

The present system of scaling in cords is designed to be simple and practical; however, there are one or two objections to it, in the writer's view. No provision is made for variation in solid cubic content per cord, due to variation in the piling and various other factors, such as size and character of the wood; the result of these variations is that the chopper and the jobber are not necessarily paid a uniform rate for their labour when they are paid a uniform rate per cord; variation due to size and character of wood may, however, be taken care of in setting the price. A further objection is that the stumpage payable per unit of cubic feet to the government is not uniform and that costs of wood for delivery to the manufacturing processes cannot be accurately determined.

Measuring in cubic feet by the same system as that followed for logs would give a more satisfactory measurement from the point of view of accuracy; the objection to this is added labour in scaling and added cost, and this objection is very important. Cost can be reduced by following some system of partial scal- 
ing, such as $100 \%$ count of pieces with measurement of every fourth pile in serial rotation, or some other proportion of the total wood selected without biass there are some objections to this, in respect to paying men working by the job and check scaling, and it might be necessary to make some special provision for this.

\section{CONCLUSION}

Considering the whole question in a broad way, it is reasonable to say that no practical system is without fault, and our object should be to find the most suitable system for the conditions under which it is to be applied. The writer strongly recommends that the matter be turned over for study to a special Committee of this Association.

The Forest Service and various companies have conducted experiments in scaling of one sort and another, and it would be an aid to such a committee if the results of these experiments could be made available to it.

The writer has tried to steer clear of the administrative features of this problem, but the technical and administrative phases of it are closely dependent on each other. There can be no solution to it without full consideration being given to all administrative features of the problem; for example, if there is to be a switch from the present Quebec Scaling System to a Cubic Foot System, various features such as stumpage rate per cubic foot and variation in the stumpage rate for different species and different diameters of pulpwood should receive consideration, in all of which matters the technical aspect should receive proper attention. 